\title{
stágio em Psicologiar discussão de exigências e critérios para o exercício de supervisor de estágio
}

Aderson Luiz Costa Jr.

Conseffeiro Vice-Presidente do CRP-01. Mestre em Psicologia, Professor do Instituto de Pstcologia da Universidade de Brasflia.

Adriano Furtado Holanda Conseltheiro secretário do CRP-01, Mestre em Psicologia, Professor do Departamento de Psicologia do CEUB (Centro de Ensino Unificado de Brasfia)-BrasiliaDF.

O estágio em Psicologia, situação prática mais distinta na formação do profissional psicólogo e forma acadêmica de profissionalização, sempre suscitou preocupações e questionamentos; parte dos questionamentos surgem quando se procede à avaliação da formação profissional de estudantes de Psicologia.

No âmbito específico da atribuiçăo do psicólogo, somente podem exercer a profissão os portadores de Diploma de Formação em Psicologia, cujo currículo mínimo prevê o Estágio Supervisionado (obrigatório) como procedimento prático de facilitação do futuro exercício profissional.

Esclarece-se que o exercício profissional é função do psicólogo, isto é, é prerrogativa deste, conforme a Lei $\mathrm{N}^{\circ}$ 4.119/62 e o Decreto No 53.464/64. Na Consolidação das Resoluçōes do Conselho Federal de Psicologia ( ${ }^{\circ} 004 / 86$ ), Título IV (do Exercício Profissional), observa-se que:

"Art. 49 - O psicólogo é pessoalmente responsável pelas atividades profissionais que exercer.

Art. 50 - Sem prejuízo do caráter privativo da atividade profissional, o psicólogo poderá delegar funções a estagiário, como forma de treinamento. análise toma como referência a legislação que trata da questäo do estágio na formação do psicólogo, enfatizando as condiçóes para o exercício da supervisão. Os autores propõem, então, uma série de encaminhamentos para serem discutidos com os psicólogos através da Autarquia, incluindo a exigência de credenciamento para supervisores de estágio em Psicologia.

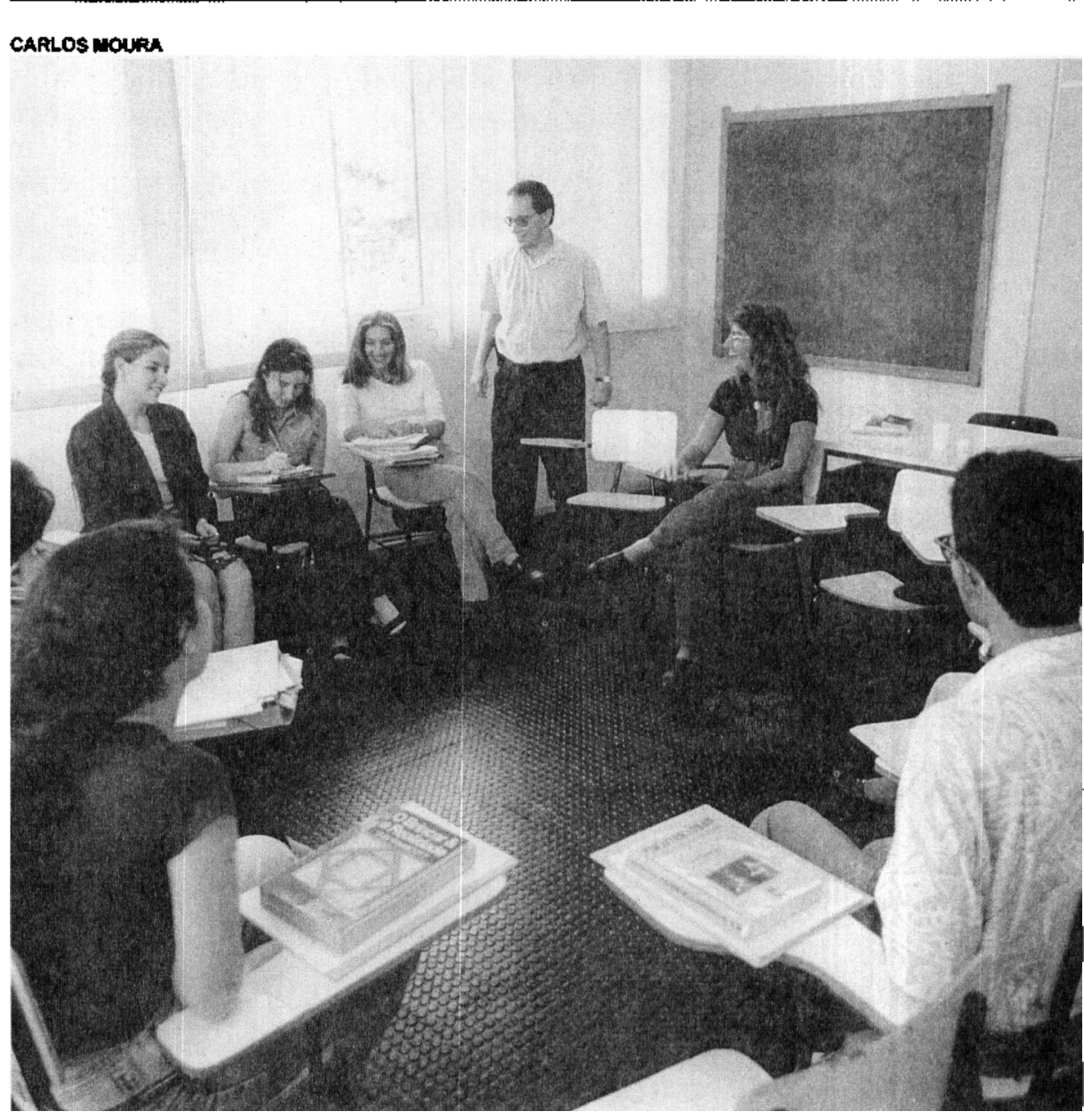




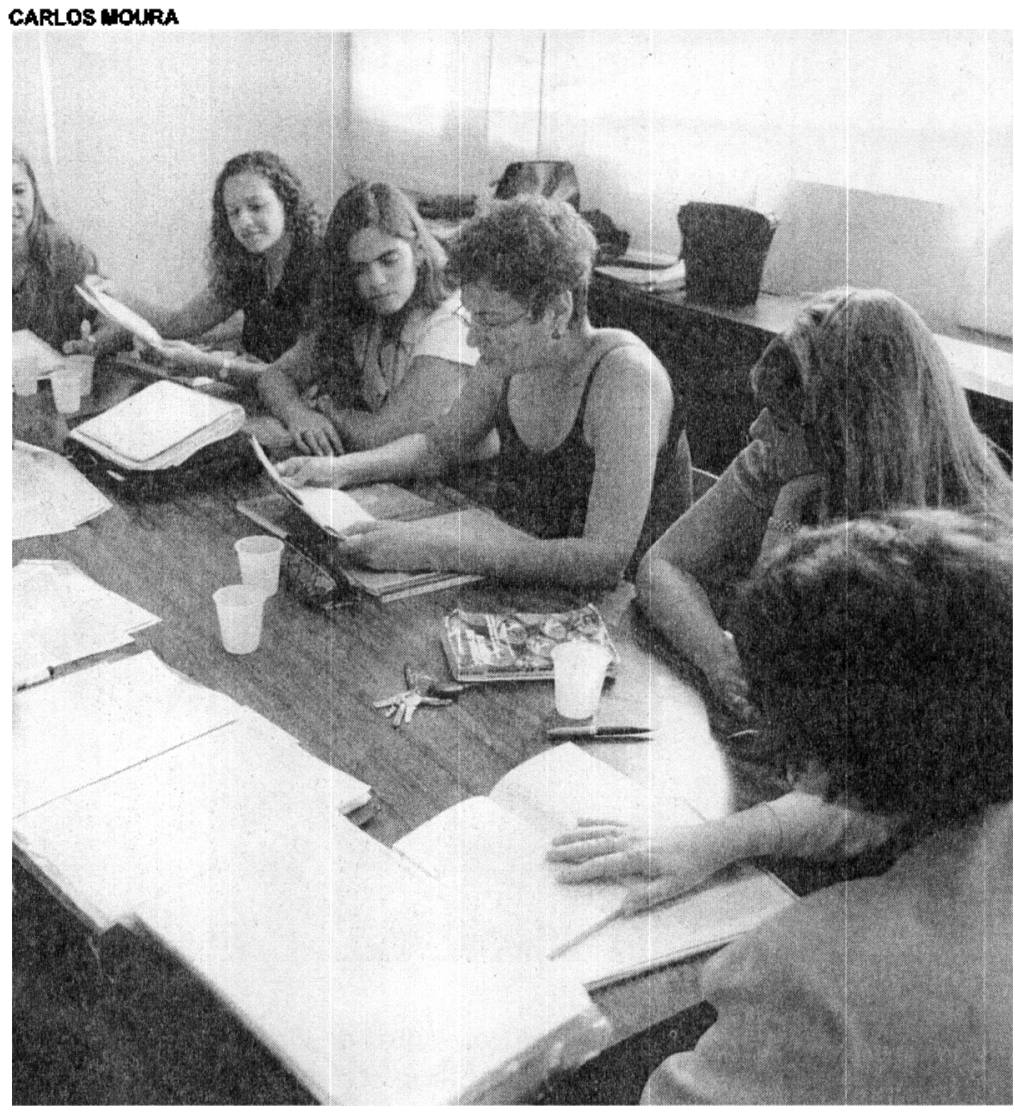

gio está contida na Lei $\mathrm{N}^{\circ}$ 6.494, de 7 de dezembro de 1977 . Sobre a referida Lei, destaca-se:

"Art. $1^{\circ}$ - As pessoas juridicas de direito privado, os órgãos da Administração Pública e as instituiçốes de ensino podem aceitar, como estagiários, alunos regularmente matriculados e que venham freqüentando, efetivamente, cursos vinculados d estrutura do ensino público e particular, nos níveis superior, profissionalizantes de $2^{\circ}$ Grau e Supletivo.

Parágrafo $1^{\circ}$ - $O$ estágio somente poderá verificar-se em unidades que tenham condiçóes de proporcionar experiência prática na linha de formaşäo, devendo, o estudante, para esse fim, estar em condições de estagiar, segundo disposto na regulamentação $d a$ presente lei.

fissionais de Psicologia por contarem com ampla demanda de estagiários. Em situações corriqueiras, como atuação em psicotécnico, o estagiário (de períodos iniciais ou medianos do curso), em nome da "oportunidade de aprendizado" aplica, avalia e elabora laudos para serem, posteriormente, assinados pelo seu suposto "supervisor" que, invariavelmente, năo exerce esta tarefa.

3) Atividades de estágio desvinculadas da aquisição prévia de conhecimentos necessários à execução da tarefa que o estagiário vai desenvolver. Ocorrem situações nas quais o estagiário é incumbido de realizar atendimento psicoterápico quando sequer tem conhecimento disciplinar sobre a matéria, ou conforme citado em Oliviera, Chermont, Glycério, César, Albuquerque \& Caldas (1970; p. 51-52), "o estagiário pode, de início, ter que fazer um diagnóstico diferencial entre oligofrenia $e$ esquizofrenia, sem ter recebido treinamento em técricas de aplicaçáo de testes, em observação de comportamento ou ainda de diagnóstico em outro tipo de cliente".

4) Ausência de controle sobre as atividades desenvolvidas, tanto pelo estagiário quanto pelo supervisor: o que compromete, certamente, a qualidade do(s) serviço(s) prestado(s).

A Legislação Especifica sobre Está-
Parágrafo $2^{\circ}$ - Os estágios devem propiciar a complementação do ensino e da aprendizagem a serem planejados, executados, acompanhados e avaliados em conformidade com os curticulos, programas e calendários escolares, a fim de se constituírem em instrumentos de integração, em termos de treinamento prático, de aperfeiçoamento técnico-cultural, cienttfico e de relacionamento humano.

Art. $2^{\circ}$ - $O$ estágio, independemente do aspecto profissionalizante, direto ou especifico, poderá assumir a forma e atividade de extensăo, mediante a participaçăo do estudante em empreendimentos ou projetos de interesse social.

Art. $3^{\circ}$ - A realizaç̧ão do estágio darse-á mediante termo de compromisso celebrado entre o estudante e a parte concedente, com interveniência obrigatória da instituiçäo de ensino.

Parágrafo $1^{\circ}$ - Os estágios curriculares serão desenvolvidos de acordo com o disposto no parágrafo $2^{\circ}$ do art. $1^{\circ}$ desta lei.

Parágrafo $2^{\circ}$ - Os estágios realizados sob a forma de ação comunitária estão isentos de celebração de termo de compromisso.

Art. $4^{\circ}$ - $O$ estágio não cria vínculo empregatício de qualquer natureza e o estagiário poderá receber bolsa, ou outra forma de contraprestaf̧ão que venha a ser centemente, a existência de organizaçб̄es que năo contratam serviços de pro- 
acordada, ressalvando o que dispuser a legislação previdenciária, devendo o estudante, em qualquer hipótese, estar segurado contra acidentes pessoais.

Art. $5^{\circ}$ - $A$ jornada de atividade em estágio, a ser cumprida pelo estudante, deverá compatibilizar-se com o seu horário escolar e com o horário da parte em que venha a ocorrer o estágio.

Parágrafo único - Nos períodos de férias escolares, a jornada de estágio será estabelecida de comum acordo entre o estagiário e a parte concedente do estágio, sempre com a interveniência da instituição de ensino.

Uma questão decisiva pode ser esclarecida a partir do Art. $3^{\circ}$ do Decreto $\mathrm{N}^{\circ}$ $87.497 / 82$, que regulamenta a lei especófica de estágios:

"Art. $3^{\circ}$ - $O$ estágio curricular, como procedimento didático-pedagógico, é atividade de competência da instituição de ensino a quem cabe a decisão sobre a matéria, e dele participam pessoas jurtdicas de direito público e privado, oferecendo oportunidade e campos de estágio, outras formas de ajuda, e colaborando no processo educativo".

Quando se estabelece que o "estágio curricular, como procedimento didático-pedagógico, é atividade de competência da instituição de ensino a quem cabe a decisão sobre a matéria", tal competência restringe-se ao modo de proceder à organização didática do tema, enquanto atividade prevista pelo currículo do respectivo curso, incluindo a definição e a oportunização de campos (áreas) de estágio, outras formas de ajuda, no sentido de colaboração com processo educativo. $O$ Artigo não prevê competência à instituição de ensino no que se refere a deliberar sobre competência(s) para o exercício profissional de supervisor de estágio.

Na posição adotada pelo Conselho Regional de Psicologia, $1^{\text {a }}$ Região, o estágio constitui uma "prática profissional concedida" a determinadas pessoas sob supervisão de um(a) psicólogo(a), competente para exercer tal atividade profissional, em uma dada área da Psicologia.' Conclui-se, deste modo, que o exercício de estagiário e de supervisor de estágio integra o terreno da orientação e da fiscalização dos Conselhos de classe, enfatizando-se o fato do exercício profissional, supracitado, estar enquadrado nas legislaçōes específicas da Psicologia.

Em estudo realizado pelo Grupo de Psicologia Clínica da antiga Associaçăo de Psicologia Aplicada (Oliveira \& Cols., 1970) foram apresentadas algumas reflexões, reproduzidas a seguir:

"O trabalho de supervisão pode ser conceituado como aprendizagem através de uma experiência supervisionada com os objetivos de:

a) proporcionar desenvolvimento profissional;

b) permitir a aprendizagem de técnicas pela prática;

c) levar d formação de atitudes e hábitos profissionais, com relação ao manejo do material e atendimento do cliente" (p. 48).

Constata-se que a atividade de estágio constitui exercício profissional, concedido sob certas condições estabelecidas. Ressalta-se o fato de que o estagiário, quando do exercício de suas funções e devidamente assistido por um profissional habilitado e disponível no momento do estágio, manipula métodos e técnicas psicológicas que, inequivocamente, são privativos do profissional psicólogo.

Assim sendo, não se pode conceder o direito de estágio a um candidato sem supervisão profissional. São necessárias, ainda, certas condiçōes com refe- rência à instituição promovedora (e responsá. vel) pelo estágio, ao supervisor e ao próprio estagiário.

$\mathrm{Na}$ questāo relativa à qualidade dos serviços prestados, por exemplo, quando da discussảo de critérios para o credenciamento de supervisores de estágio, tem-se argumentado contrariamente ds indicações de titulação, tempo de formado, experiência prévia com supervisão, pois estes critérios não garantiriam a qualidade da supervisão. Pode-se concordar, parcialmente, com esta alegação, na medida em que, ir contra tais critérios - apenas - sem alternativas outras, parece firmar um procedimento de acomođação com o já disposto que, por seu turno, não garante qualquer qualidade e nem mesmo prevê, sequer, a possibilidade de uma qualidade. $O$ fato de haver dificuldades no estabelecimento de critérios normativos com respeito a determinada atividade não significa a sua impossibilidade.

Segundo os citados autores, o conjunto de critérios aos quais se referem são:

A) Quanto à instituição: integração da atividade no plano da organizaçăo, planejamento de atividades do estagiário (funções e responsabilidades), condições físicas e integração do estagiário à equipe de trabalho da instituição.

B) Quanto ao estagiário: motivação para a atividade (conhecimento para a tarefa e dedicaçăo para o exercício, desvinculando o estágio de mera complementação de horas para formação); desejo de integração à equipe; e "formaçăo teórica ou prático-teórica ao nivel do trabalho que deve realizar" (ressalta-se a inadequação corrente em cursos de graduação em Psicologia, que muitas vezes impõem ao estagiário uma condição de aprendizagem "in loco" sem prévio conhecimento da atividade, implicando prejuizo(s) à formaçăo do estagiário, inadequada prestação de serviços, conduta antiética e demérito à profissão).

C) Quanto ao supervisor, definido como "aquele que procura levar o estagiário a descobrir por si mesmo as respos- 
tas para os problemas que surjam durante o trabalho", consideram-se os seguintes critérios (Oliveira \& Cols., 1970, p. 49): formação teórica e experiência, integração na equipe e na estrutura da organização, satisfação com a tarefa de supervisor e segurança.

Em outro estudo (Witter \& Cols.), investigou-se aspectos relativos à estrutura, responsabilidade e controle de qualidade dos estágios supervisionados, verificando-se a ocorrência, ao longo do tempo, de mudanças em direção ao aprimoramento dos mesmos. Dentre as mudanças - que evidenciam uma preocupação com a qualificação da profissionalização - tem-se a ampliação de opções de estágio (criação ou modificaçẳo de áreas), o credenciamento de supervisores, modificações na metodologia ou sistemática do estágio, estabelecimento de normas e regimentos e reestruturação de serviços.

Os autores destacam que "é preciso pesquisar a organização, ofuncionamento e eficiência destes centros [de atendimento psicológico das instituiçóes formadoras], corporativamente aos serviços independentes, para detectar qual a forma que garante melhor formaçäo ao futuro profissional e que facilita mais sua inserção na realidade e no mercado de trabatho. Certamente, a eficácia e a eficiência de um estágio estão relacionadas com $o$ controle de qualidade do mesmo, o que se espera seja efetivado pelos responsáveis por sua realização" (Witter \& Cols., 1992, p. 191).

A preocupação com a necessidade de acompanhamento do Estágio por parte dos Conselhos de Psicologia se deve ao fato de que, além de se constituir em exercício profissional, o estudo verificou que "todas as respostas enfocaram a avaliação do estagiário, não havendo qualquer menção à avaliação do supervisor ou mesmo do estágio enquanto atividade acadêmica ou de formaçāo profissional, aspectos hoje considerados imprescindiveis em qualquer avaliação institucionale de formação profissional" (Witter \& Cols., 1992, p. 194).

O mesmo estudo mostrou que há grande variação na concepção do estágio acadêmico em termos de sua prática. Para exemplificar, verificou que o número de turmas de supervisão (por semestre) varia de 01 a 80 ; igualmente o número de supervisores (de 4 a 86).
Uma das variáveis relevantes ao trabalho de supervisão é a carga horária do profissional, que variou de 01 a 20 horas por turma.

Como se vê, a atividade de estágio requer uma organização mínima, necessária à formação do futuro profissional. Acrescenta-se que a única exigência que - graduado tem de cumprir para exercer a sua profissão é estar inscrito no seu Conselho de classe. Não há, no Brasil, especialização a nível de graduação na área de Psicologia; a formação de nossos psicólogos nấo atribui definiçōoes de áreas de atuação, não sendo pois possivel ao usuário ter acesso a dados necessários acerca da formação técnica do profissional.

Neste sentido, critérios de estágio bem definidos poderiam amenizar eventuais dificuldades que venham a surgir quando do exercício profissional do psicólogo. A responsabilidade da orientação do exercício profissional deve ser dividida com as agências formadoras, ou então assumidas em definitivo pelos Conselhos de classe.

As dificuldades são diversas e surgem nas mais diversas áreas de atuação do psicólogo, desde o atendimento clínico (em psicoterapia, unidade básica de saúde, unidade hospitalar, saúde mental) até o psicotécnico e psicodiagnóstico. E necessário um posicionamento oficial dos Conselhos
Regionais de Psicologia no sentido de salvaguardar a formação profissional e o futuro exercício da profissão.

A seguir, são explicitados tuma série de argumentos, previstos pela legislação em vigor, relativos às exigências para o exercício da função de supervisor de estágio em Psicologia:

1) A prática de Estágio Supervisionado se constitui, tanto para o estagiário quanto para o supervisor de estágio, em exercício profissional (Lei $\mathrm{N}^{\circ} 6.494$ e o Decreto $\mathrm{N}^{\circ} 87.497$, de 18 de agosto de 1982 , que regulamenta a Lei $\mathrm{N}^{\circ}$ 6.494). Segundo o citado Decreto (Art. $2^{\circ}$ ), "considera-se estágio curricular, para os efeitos deste Decreto, as atividades de aprendizagem social, profissional e cultural, proporcionadas ao estudante pela participação em situaçôes reais de vida e trabalho de seu meio..."

2) Constiuui atribuição do Conselho Regional de Psicologia (Lei No 5.766) orientar, aperfeiçoar, disciplinar e fiscalizar o exercício da profissão de psicólogo em sua área de competência, bem como zelar pela fiel observância do Código de Ética Profissional, impondo sanções pela sua violação (Art. $9^{\circ}$, alíneas "b" $\mathrm{e}$ "c"), zelar pela dignidade e independência da profissão de Psicólogo.

3) Segundo a Lei $N^{\circ} 4.119$ (que dispõe sobre os cursos de formação em Psicologia e regulamenta a profissão de Psicólogo), no capítulo referente aos direi-

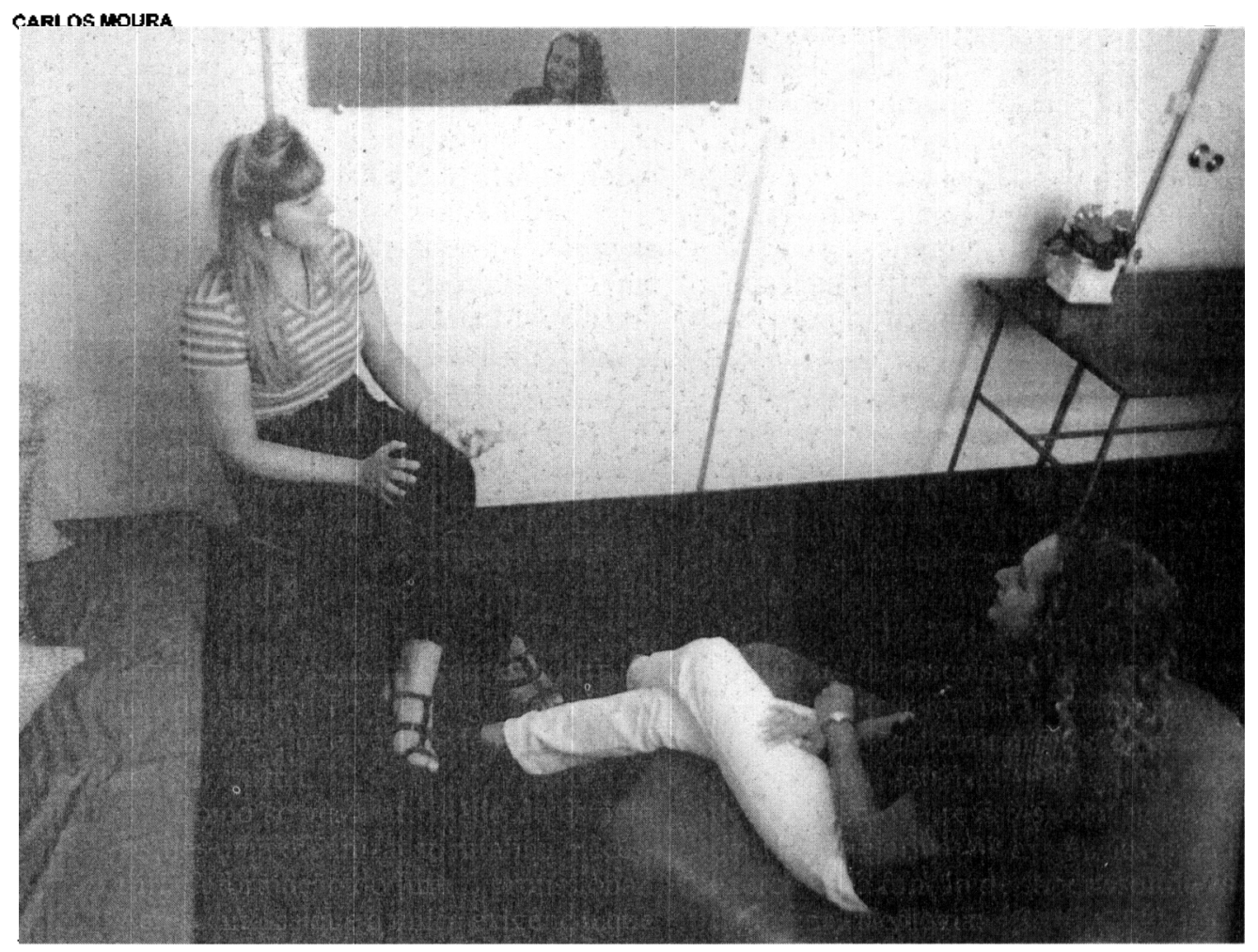


tos conferidos aos diplomados (Capítulo III), observa-se que (Art. 13), ao portador do diplorna de Psicólogo é conferido o direito de ensinar Psicologia nos vários cursos de que trata esta lei, c. servadas as exigências legais específicas, e a exercer a profissão de Psicólogo.

4) Observa-se, entretanto, que segundo a Lei $\mathrm{N}^{\circ} 4.119$ (supracitada), para o exercício profissional de Psicólogo é necessário ser portador de diploma de graduação em Psicologia, o qual deve ser registrado no órgão competente do MEC (Lei $\mathrm{N}^{\circ} 4.119$, Capítulo III, Art. 10 e, Decreto $N^{\circ}$ 53.464, que regulamenta a Lei $\mathrm{N}^{\circ} 4.119$, Art. $3^{\circ}$ ) e, ainda, é necessário possuir inscrição profissional no Conselho Regional de Psicologia da res. pectiva região de atuação (segundo Decreto $\mathrm{N}^{\circ}$ 79.822 , Art, 01, que regulamenta a Lei $\mathrm{N}^{\circ}$ 5.766).

5) Embora o docente de ensino superior exerça, em suas atividades acadêmicas, a profissão de professor de magistério superior e não a CARLOS MOURA profissão de Psicólogo, quando se tratar de um docente no exercício de supervisor de Estágio, o mesmo deve está exercendo a profissão de Psicólogo, devendo, obrigatoriamente, cumprir as exigências legais (e específicas) de que trata a legislação (acima referida, nos itens 3 e 4 desta argumentação).

6) Ainda em referência à Lei $N^{\circ}$ 4.199 (Art. 13, parágrafo $1^{\circ}$ ), ressaltase que constitui função privativa do Psicólogo (restrita ao psicólogo) a utilização de métodos e técnicas psicológicas com objetivo de diagnóstico psicológi$c o$, otientação e seleção profissional, orientação psicopedagógica e solução de problemas de ajustamento.

7) Acrescente-se, que segundo Decreto $\mathrm{N}^{\circ} 53.464$, Art. $4^{\circ}$, são funções do Psicólogo, além da citada no item anterior, as seguintes: ensinar as cadeiras ou disciplinas de Psicologia nos vários níveis de ensino, observadas as demais exigências da legislação em vigor; e, supervisionar profissionais e alunos em trabalhos teóricos e práticos de Psicologia.

8) Considerando a Resolução CFP $\mathrm{N}^{\circ} 004 / 86$, que institui a consolidação das resoluçōes do Conselho Federal de Psicologia e conceitua todos os termos utilizados no Art. 13 (Parágrafo $1^{\circ} \mathrm{da}$ Lel $N^{\circ} 4.119$ ), no que se refere às técnicas e métodos psicológicos, eliminando quaisquer dúvidas ou eventuais interpretações (divergentes) acerca da definição e do entendimento de tais técnicas e métodos psicológicos, considera-se impossível conceber um Estágio Supervisiona-

(atuação prática) dos alunos, no âmbito interno e externo da instituição de ensino universitário".

10) Constitui entendimento desta argumentação, considerando o conteúdo explicitado até o momento, que apenas profissionais Psicólogos (portadores do diploma de graduação em Psicolo. gia, reconhecido por órgão competente, e devidamente inscritos no Conselho Regional da respectiva área de competência) têm o direito adquirido, por lei, de supervisionar Estágio em Psicologia.

11) Esclarece-se que a Lei de Autonomia Universitária não pode ser utilizada para justificar a prática de supervisão de Estágio em Psicologia por docentes não Psicólogos, uma vez que se trata de uma atividade proibida por lei. Acrescenta-se, ainda, que a Lei de Autonomia Universitária se restringe a atividades didático-científicas, administrativas e de gestão financeira, enquanto que a supervisão de

do em qualquer área da Psicologia (incluindo objetivos gerais e específicos, atividades desenvolvidas, procedimentos e critérios de avaliação) sem utilizar o emprego das técnicas e métodos psicológicos (privativos do psicólogo) citados no Art. 13, da Lei $N^{\circ} 4.119$.

8.1) Observa-se que mesmo que fosse possivel a existência de um Estágio em tais condições, o mesmo só poderia ser supervisionado por profissionais psicólogos, uma vez que se trata de exercício profissional. Qualquer outro profissional, não Psicólogo, que realize tal atividade estaria exercendo prática ilegal da profissão de psicólogo.

9) Ressalta-se, ainda, que segundo as Atribuiçōes Profissionais do Psicólogo no Brasil (Contribuição do Conselho Federal de Psicologia ao Ministério do Trabalho para integrar o Catálogo Brasileiro de Ocupaçôes - enviada em 17 de outubro de 1992), constitui atribuição do Professor de Psicologia (do Ensino Superior), entre outras: Item 5 "possuir a habilitação mínima de bacharel em Psicologia ou grau de Psicólogo", e, Item 6: "supervisionar estágios curriculares
Estágio constitui prática de exercício profissional, competência atribuída (Lei No 5.766) aos Conselhos Regionais de Psicologia.

12) Reconhece-se que as instituições de ensino superior têm o direito de permitir que seus docentes, sem formação de graduação em Psicologia, mas com qualificação acadêmica reconhecida (segundo critérios estabelecidos pela própria instituição de ensino), possam ministrar disciplinas do curso de graduação em Psicologia. Entretanto, institujção de ensino não possui autonomia para autorizar tais docentes, sem formação em Psicologia, a supervisionar Estágio em Psicologia. Permitindo que estes docentes supervisionem Estágio em Psicologia, a instituição estaria autorizando-os a exercer ilegalmente a profissão de Psicólogo.

13) Os Conselhos Regionais de Psicologia, considerando suas atribuições de orientador, disciplinador e fiscalizador do exercício da profissão de Psicólogo, têm o direito de exigir o cumprimento da legislação (todo docente, no exercício de supervisão de estágio, 
deve estar inscrito no Conselho Regional da área de sua Jurisdição).

13.1) Observa-se que alguns Conselhos Regionais de Psicologia, objetivando o cumprimento do disposto na Legislação, já emitiram posicionamentos quanto ao referido tema. Exemplifica-se:

13.1.a) Conselho Regional de Psicologia, $6^{\mathrm{a}}$ Região (Estado de São Paulo - SP), em parecer da Assessoria Jurídica, aprovado em 01 de setembro de 1992, sobre a obrigatoriedade de Registro do Professor junto aos Conselhos Regionais de Psicologia, observa que " $a$ exigência de Registro no Conselho Regional será obrigatória, caso o Professor seja contratado para desenvolver, além das atividades do magisterio, a supervisão acadêmica ou extra-acadêmica ou outra da mesma natureza, independentemente da designação adotada contratualmente, uma vez que entendemos ser a SUPERV$S A \tilde{O}$ atividade que envolve diretamente $\mathrm{o}$ exercício profissional do Psicólogo". O citado parecer, ainda esclarece que "nada impede, evidentemente, que o Professor, além desta função, exerça simultaneamente a função de Psicólogo na mesma instituiçấo ou em outra e, nesta modalidade, estará, sem dúvida, obrigado ao registro perante o Conselho Regional de sua área de açäo".

13.1.b) Conselho Regional de Psicologia, $8^{a}$ Regiāo (Estado do Paraná PR), em parecer da Assessoria Jurídica, datado de 17 de fevereiro de 1993, sobre a necessidade de inscrição de Professores de Psicologia, nos Conselhos Regionais de Psicologia, conclui que "não há qualquer dúvida, até por ter usado o legislador o mesmo termo - função - existente na Lei $N^{\circ} 4.119$, que ao ser regulamentada este diploma legal, - quis significar o regulamento, que ensinar Psicologia é uma funcão Psicológica", e propõe a obrigatoriedade do professor de Psicologia estar inscrito no Regional de sua área de Jurisdição. $O$ citado Parecer observa, ainda, considerando que uma das funçōes do Psicólogo é supervisionar profissionais e alunos em trabalhos teóricos e práticos de Psicologia (conforme já explicitado no item 07 desta argumentaçāo), "que aqueles que irão formar novos profissionais terão de ter o domínio e o conhecimento das técnicas e métodos próprios da ciência que irão transmitir. Isto não poderia ser de outra forma, impondo-se como dever social". Desta forma, ressalta o parecer, "teremos profissionais aptos a aplicar as fun- çôes psicológicas".

Baseado no disposto até o momento, sugere-se alguns encaminhamentos aos Conselhos Regionais de Psicologia:

1) Definição, de acordo com a lei, da atividade de supervisão de estágio em Psicologia como atividade privativa de Psicólogos, exigindo-se destes que estejam devidamente habilitados $\mathrm{e}$ inscritos em seus respectivos Conselhos Regionais de Psicologia. Convém assinalar que esta sugestão já conta com ampla aprovação no meio acadêmico, conforme estudo de Witter \& Cols. (1992); estes autores observaram, a partir da amostra estudada, que $92,85 \%$ das instituições exigem do supervisor de estágio o registro em seu respectivo CRP.

2) Defínição da obrigatoriedade do estágio estar diretamente vinculado a uma instituição de ensino, onde o estagiário estará cursando regularmente o ciclo profissional. Caso contrário, isto deve ser encarado como exercício ilegal da profissão por parte do estagiário e infração ao código de Ética Profissional dos Psicólogos para o supervisor.

3) Os Conselhos Regionais de Psicologia poderiam manter controle sobre os supervisores de estágio para um acompanhamento mínimo de suas atividades; em especial, no tocante à formalização do estágio em si, e não apenas da isenção de responsabilidade direta sobre a atividade por parte do profissional.

4) Os Conselhos Regionais de Psicologia deveriam manter estreito contato com as agências formadoras no sentido de orientá-las, principalmente quando o estágio ocorre fora da agência for-

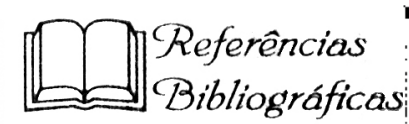

BUYS, R.C. (1978). Supervisăo de Psicoterapia na Abordagem Humanista Centrada na Pessoa, São Paulo: Summus Editorial.

Conselho Federal de Psicologia (1995). Psicologia - Legislaçåo. Brasilia: CFP.

Ministério do Trabalho (1994) Classificaçăo Brasileira de Ocupações. Brasília: SPES.

OLIVEIRA, A.F., CHERMONT, J.M.A., GLYCÉRIO, L.M.I.M., CÉSAR, S.C., ALBUQUERQUE, T.L. \& Caldas, Y. (1970). O Estágio Supervisionado: Estudo Preliminar. Arquivos Brasileiros de Psicologia, 22 (2): 47-53.

SOARES, A.R. (1983). O direito privativo do psicólogo. Psicologia: Ciência e Proflissâo, 3 (2), 01.07 .

WITER, G.P., GONÇALVES, C.L.C., WITTER, C., YUKIMITSU, M.T.C.P. \& NAPOLTANO, J.R. (1992). Formação e Estágio Académico em Psicologia no Brasil. Em: Conseho Federal de Psicologia (Ed). Psicólogo Brasileiro - Construção de Novos Espaços. Campinas: Editora Átomo. madora, sendo relevante "verificar como essa agência controla o mesmo, se delega ao profissional da outra instituição, se um supervisor da própria escola se encarrega p. 196).

5) Os Conselhos Regionais de Psicologia deveriam manter uma comissão alizaria, periodicamente, reuniões com os supervisores, no intuito de debater Sues relativas as suas atividades. encontros de trabalho entre os estagiários de Psicologia e os supervisores de estágio (docentes), sob promoção do

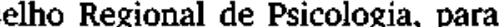
tindo maior integração entre os Conseos de classe e agências formadoras. cologia deveriam repensar a possibilimo. Neste sentido temos a sugerir os seguintes: obrigatória inscrição no Consetrês seria necessário); obrigatoriedade . va experiência na mesma) e comprovação de especialização (qualificação mínima exigida) na área a ser superuma aproximação dos Conselhos (em especial o Conselho Federal de Psicolocunas existentes na formação de nossos profissionais. 